\title{
Étienne Balibar, La igualibertad
}

(2017) Herder

Barcelona, $496 \mathrm{pp}$.

\author{
Ricardo Cueva Fernández \\ Universidad Autónoma de Madrid \\ ORCID ID 0000-0003-2629-4652 \\ ricardo.cueva@uam.es
}

Cita recomendada:

Cueva Fernández, R. (2019). Étienne Balibar, La igualibertad. Eunomía. Revista en Cultura de la

Legalidad, 17, 414-417.

doi: https://doi.org/10.20318/eunomia.2019.5047

Etienne Balibar es, sin duda alguna, uno de los principales representantes de la intelligentsia francesa posmarxista. Habiendo participado en aquel famoso volumen sobre Para leer El capital, cuyo principal mentor fue Louis Althusser, sin embargo, luego su obra ha tomado derroteros un tanto alejados de sus orígenes, aunque sin perder de vista en ningún caso los posibles contenidos emancipatorios de la filosofía política (o, por decirlo de otro modo, vertiendo sus preocupaciones sobre «la dominación», según reza su propio texto: p. 22).

El título del volumen que aquí me ocupa no evoca, a pesar de tan sugerente, un tratado completo de ningún tipo, algo que en realidad además Balibar ha eludido siempre, sino que engloba un conjunto de ensayos entre los cuales el que sirve para denominar al libro es uno de los más destacados. Así, y según nos cuenta el propio autor en el Prefacio, quedan reunidos tres grupos de textos que cubren nada menos que casi veinte años (desde 1989) y que son paralelos al resto de la labor que ha ocupado a Balibar durante ese período. El primero expondría la «idea general de una dialéctica de la insurrección y la constitución» en torno a la llamada, en efecto, «igualibertad», el segundo juntaría varios análisis críticos sobre diversos autores (Arendt, Poulantzas, Laclau, etc...) y la tercera parte reuniría varias intervenciones a partir de episodios contemporáneos de carácter social, muy especialmente los relativos a disturbios y polémicas acaecidas hace unos años en Francia. Tal suma irregular y a menudo desigual de escritos deja al lector un extraño regusto en el cual destacan análisis lúcidos y una distancia saludable respecto al ensoberbecimiento de otros autores coetáneos, así como un grado de honestidad también relevante, pero todo ello mezclado con numerosas indefiniciones en un estilo a menudo poco preciso y que, por situarse fuera de la tradición del pensamiento marxista más asentada, procura alejarse de ella pero sin penetrar con cierto rigor en determinadas materias. 
Pero voy a centrarme un tanto más en el volumen, porque sin duda lo merece, y sobre todo en algunos rincones. En la primera parte del libro, así, Balibar muestra una especial preocupación por los derechos y su formulación (si bien más política que jurídica). Pese a lo que se venga a señalar habitualmente, en primer lugar (y esto es algo con lo que quizás coincidiría de nuevo con los republicanos, aunque desde otro punto de partida muy distinto), la democracia y la ciudadanía no guardan relación directa entre sí; de hecho, ambas dependen de una misma antinomia que impulsa «las transformaciones de la institución política», y que por añadidura en ciertos momentos puede hacerse particularmente visible y derivar en crisis (18-19).

Por tanto, el autor francés se propone abordar tres distintos aspectos de esa dialéctica entre democracia y ciudadanía. Así, y en primer término, seguir la huella de la «igualibertad» (que residiría en «un diferencial de insurrección y de constitución», p 19), examinar la contradicción en que se debate la ciudadanía social típica del Estado del Bienestar (y que prefiere denominar «Estado nacional-social»), y por último analizar en qué medida la respuesta neoliberal a su crisis, mediante la promoción ilimitada del individualismo y del utilitarismo, la conversión del hombre en un ser que actúa conforme al cálculo económico y por tanto en la antipolítica (p. 54), atrae un peligro mortal para la propia democracia (p. 20). En medio de todo ello, además, Balibar nos aclara que prefiere referirse siempre al actor político de esa democracia, antes que a sujeto de la política (ídem).

En torno al primer aspecto, en que quiero detenerme por un momento, Balibar entiende que la libertad y la igualdad se hallan en el mismo nivel, que serían las dos caras del poder constituyente, sin poseer ninguna una prioridad ontológica o epistemológica una en relación con la otra. La igualibertad no es una disposición originaria, ya que los dominadores nunca ceden con facilidad sus privilegios o su poder (de forma «voluntaria», diríamos, p. 22) y tal extremo engendra el conflicto y ,por tanto, la necesidad de legitimar la lucha consiguiente: «lo que vemos es una incompletitud esencial del 'pueblo' en cuanto cuerpo político, un proceso de universalización que pasa por el conflicto y por la 'negación' de la exclusión» (p. 23), dice Balibar aludiendo a "la parte de los que no tienen parte» de Rancière. La insurrección, pues, «representa una posibilidad permanente». La comunidad política, con su consiguiente articulación de la ciudadanía «no es ni realizable como unidad homogénea de sus miembros ni representable como una totalidad consumada» ( $p$. 24). Tal ciudadanía no puede identificarse, hoy por hoy, con nacionalidad (p. 26).

Asimismo, esa ciudadanía se configuró a partir de la finalización de la Segunda Guerra mundial, en numerosos Estados del mundo como los europeos, con carácter «social». Pero no solo reconociendo la existencia de una serie de derechos (a prestaciones educativas, asistenciales, sanitarias, así como a derechos laborales de distinto cuño), sino también universalizándolos: de otra manera el Estado-nación no hubiera podido sobrevivir en esos lugares (p. 48). De hecho, esta es la base para que el socialismo del siglo XIX y del XX tenga una contradicción inmanente, preso como se halla tanto del progresismo (sin sentido peyorativo, como búsqueda del avance) como del estatismo, y de forma que así la esfera pública ( $y$, por tanto, política) es identificada con la comunidad nacional (p. 51).

Frente a tal movimiento, el neoliberalismo rampante tiende a configurar regímenes, no tanto antidemocráticos, como ademocráticos, «en el sentido de que los valores inherentes a las reivindicaciones de derechos (la igualibertad) ya no desempeñan ningún papel» (p. 57). El «individualismo negativo» se basa en que las personas «moralicen su propia conducta sometiéndose por sí mismos al criterio de la utilidad máxima o el devenir productivo de su individualidad», arruinando así las instituciones de aseguramiento social y las formas de solidaridad o de socialización 
que hacían posible la afiliación de los individuos a una comunidad de ciudadanos ( $p$. 63).

La solución para frenar ese proceso de «desdemocratización» (y en el cual la palabra democracia se banaliza hasta perder su significado), pasa por redefinir el sujeto que pueda hacerle frente e incluso avanzar en sentido contrario. Balibar señala que las figuras del marginal y el militante, pese a surgir a menudo separadas, no tienen por qué hallarse desvinculadas luego en la práctica. Es verdad que «la representación clásica de la praxis revolucionaria, que reúne 'rebelión' y 'transformación', las había fusionado en un solo tipo ideal», y esto, aunque simbólicamente correspondieran «a formas de acción distintas» y sustentadas por prácticas sociales diferentes (p. 73). Pero, en cualquier caso, urge buscar quiénes son los actores políticos «a través de ciertas formas de subjetividad, y no en términos de armonía preestablecida entre condiciones sociales que existirían 'en si' y formas de conciencia y organización política que les permitirían existir también 'para sí', desde el punto de vista del progreso histórico» (p. 73). De modo que esas "unidades de acción o las alianzas se justifican siempre por el descubrimiento de que múltiples formas de desigualdades o de exclusión pertenecen a un mismo 'sistema', y por consiguiente pueden contribuir a un mismo proceso de democratización de la ciudadanía» (p. 73, o «democratización de la democracia»). Dichas combinaciones, además, «no tienen ninguna base natural, ya se la piense en términos ontológicos o en términos de destino moral», porque «la esfera de la acción política no está dada o prefigurada; es 'faltante', como el pueblo mismo».

Los contornos, pues, de lo que pretende desarrollar Balibar en el resto del volumen (aun de forma accidental, si lo observamos como recopilación), quedan definidos desde un primer momento. El resto de páginas es una profundización en dichas premisas a través de varios conceptos.

El primero de ellos, y que traigo precisamente a colación por ser el que podría interesar más en esta publicación, es el de «derechos». Hemos visto como su vinculación a la ciudadanía parece clara, pero, hablando de la Declaración de 1789, Balibar hace una puntualización importante y que conecta con sus preocupaciones sobre la xenofobia que luego examinaremos: realmente aquel concepto está sustentado en las instituciones de la ciudad Estado griega, no por la identificación de la igualdad y la libertad, sino por la tesis «de la igualdad dentro de los límites de la libertad, considerada como un estatuto social fundado», a su vez, y «según los casos, en una tradición, una constitución o una cualidad natural de los individuos». En la antigua polis, por mucho que a algunos nostálgicos les pese, la igualdad no era ni una consecuencia ni un atributo de la libertad (p. 94). La Declaración de Derechos del Hombre y del Ciudadano de 1789 sí que habría supuesto en cambio esa identificación, y por ello habría sido novedosa y revolucionaria: la igualdad es la medida de la libertad y lo mismo ocurriría a la inversa, constituyéndose con tal interrelación la «proposición de la igualibertad» (p. 96). La distinción entre libertades individuales y colectivas carece de sentido, pues la igualibertad trataría «del grado de igualdad que es necesario para la colectivización de las libertades individuales, y del grado de libertad que es necesario para la igualdad colectiva de los individuos, siendo la repuesta siempre la misma: el máximo de condiciones determinadas» (p. 100, vid. también $p$. 180 , cuando habla de la «interdependencia lógica» entre ambas, o 211, cuando señala su «perfecta equivalencia»). Las diferentes coerciones que ataquen la libertad o que erijan desigualdades son, en realidad, convergentes. Balibar, así, busca cómo «instituir lo transindividual, encontrar una institución de lo político en la que ni el individuo ni la comunidad, ni la libertad ni la igualdad, pueden existir sin su contrario» (p. 183). 
Esto hace que el autor francés, así, se encamine hacia los mecanismos que puedan ayudar a suprimir la exclusión de ciertas personas de la razón pública (p. 194). El objetivo a perseguir sería, pues, «a la vez defender y extender la ciudadanía social» e «inventar nuevas normas, un nuevo concepto de ciudadanía, que en particular permita superar las muy profundas contradicciones del Estado nacional-social» (p. 271). ¿De dónde vienen esas contradicciones? La respuesta de Balibar parece apuntar al fenómeno de la globalización (p. 35; y que incluiría la gran desigualdad de acceso a recursos y de degradación medioambiental de amplias zonas del planeta), que a su vez origina crecientes fenómenos xenófobos. En este punto, además, el autor francés propone una «ciudadanía transnacional» que suponga «la democratización de las fronteras, la gestión concertada, negociada con los interesados y los países de partida, flujos de inmigración, el reconocimiento de los derechos cívicos y políticos a los inmigrantes», así como "el reconocimiento del pluralismo cultural y de su contribución al desarrollo de cada cultura nacional» (p. 273). Algo en lo que insiste en el penúltimo capítulo del libro ("Hacia la cociudadanía").

Pero algunos problemas específicos que parecen quedar en el tintero afloran en seguida con el curso de los acontecimientos, muy especialmente de los acaecidos en Francia. Es por ello que la tercera parte del texto (no queremos abundar en la continuación de la segunda, en la que Balibar realiza interesantísimos comentarios sobre diversos autores), el académico francés se dedica a profundizar en el fenómeno de la exclusión en aquel contexto nacional: en concreto, en lo que denomina la «exclusión interior». Se trataría, así, de dilucidar la configuración como ciudadanos de segunda de una serie de personas, que, incluso aun teniendo reconocida formalmente su ciudadanía (por ejemplo, muchos hijos o nietos de inmigrantes que incluso se habrían educado en suelo francés), se encontrarían con obvios obstáculos para desenvolverse como sujetos de derechos y ser considerados como auténticos iguales por el Estado y el resto de sus conciudadanos. Balibar va examinado así diversos casos, como el de la polémica sobre el hiyab y el laicismo (pp. 347-386) y las revueltas de los suburbios franceses del 2005 (pp. 387-436), abogando por «una democracia social, cosmopolítica, antiautoritaria» (p. 373).

No puede por menos, que encomiarse el esfuerzo de Balibar por superar los límites del constreñimiento que numerosos estudios sobre la democracia (en gran parte anglosajones) han contribuido a situar en el pensamiento de nuestra época. Para ello se encuentra pertrechado con un poderoso arsenal (transcrito en una amplísima bibliografía), y que abarca de Hegel a Poulantzas, de Althusser a Rancière, de Marx a Arendt. Pero su intento de escapar de modelos de teorización de la democracia, pese a resultar elogiable, da origen a una descripción a menudo vaga de diversos fenómenos que requerirían un tratamiento más exhaustivo ( $\mathrm{y}$ a menudo comparativo) y que se presentan en distintos rincones del planeta. Pero, sobre todo, padece un defecto muy frecuente entre los denominados autores "posmarxistas», digámoslo así, "de buena voluntad», y es el de pretender borrar al sujeto de las transformaciones sociales para, a continuación, recrearlo a través de una serie de simpatías inmediatas con determinadas rebeliones, revueltas o movimientos, sin hallar una explicación demasiado coherente para sus intuiciones. La justificación que tendría para ello, resulta claro, sería de carácter moral, y a eso parece señalar su continua apelación a la igualdad y la inclusión. El problema es cómo conseguir apuntalarlas sin definir algunos contornos más nítidos en torno a la protesta, y cómo hacerlo sin una crítica a la economía política, que fue al fin y al cabo el mejor intento que nos dejó Karl Marx para construir un pensamiento que pusiera en cuestión lo dado. 